\title{
The Effectiveness of Clinical Pharmacist Intervention in Reducing Drug Related Problems of Childhood Acute Lymphoblastic Leukemia Patient in Tangerang District General Hospital, Indonesia
}

\author{
Rizky Farmasita Budiastuti ${ }^{*}$, Maksum Radji1, Rini Purnamasari² \\ ${ }^{1}$ Faculty of Pharmacy, Universitas Indonesia, Depok, Indonesia \\ ${ }^{2}$ Department of Pediatric, Tangerang District General Hospital, Indonesia
}

\begin{abstract}
This study aimed to evaluate the clinical pharmacist interventions in reducing drug-related problems (DRPs) in childhood acute lymphoblastic leukemia (ALL) patients in the Tangerang District General Hospital, Banten, Indonesia. This study used a prospective analysis of patients with a pre-post design between January-March 2017. The Pharmaceutical Care Network Europe (PCNE) (V6.2) pre-post study system was used to identify the DRPs of 138 patients. The Pharmacist interventions were addressed to physicians, patients, and other health professions to determine the effectiveness of pharmacist interventions before and after the intervention. The number of identified DRPs was 177 problems and the identified types of DRP was 164 types. The pharmacist interventions significantly decreased the DRPs from 177 to 10 DRPs $(\mathrm{p}<0.05)$ and type of DRPs from 164 to 10 types of DRPs $(p<0.05)$. Risk factors for nutritional status, type of ALL, comorbidities, number of drug items, and type of treatments did not significantly affect $(p>0.05)$ to the decreased of the number and type of DRPs. Clinical pharmacist interventions able to reduce the number and type of DRPs and can improve treatment outcomes in childhood ALL.
\end{abstract}

*corresponding author

Keywords: chemotherapy; childhood acute lymphoblastic leukemia; DRPs; pharmacist interventions

Email: rizky.farmasita.b@gmail.com

\section{INTRODUCTION}

WHO data reported the prevalence of childhood cancers is accounting for $0.5 \%$ to $4.6 \%$ of all cancers. The total incidence rates of childhood cancer vary between 50 and 200 per million children worldwide. In general, leukemia constitutes about a third of all cancer in childhood (WHO, 2017). A number of 11,000 cases of childhood cancer have been reported each year in Indonesia and 1957 cases of acute lymphoblastic leukemia (ALL) in children occurred in 15 hospitals in Indonesia around 2007-2012, in which approximately 650 cases developed in Jakarta (Ministry of Health of the Republic of Indonesia, 2015).

Most of the childhood cancer cases appear without specific symptoms causing a delay in the diagnosis of cancer. Inaccurate diagnosis of cancer, inadequate equipment and medication in hospitals lead to disease complications. The lack of cancer-related knowledge in primary care providers also renders the effectiveness of cancer treatment (Ministry of Health of the Republic of Indonesia, 2015).

The incidence of childhood leukemia under the age of 15 years is about 4-4,5/100,000 children per year while the highest frequency occurs at the age of 2-5 years (Basic Health Research, 2013). The onset of acute lymphoblastic leukemia (ALL) usually develop unexpectedly and can lead to death if not treated properly. The appropriate treatment increased the life expectancy of patients significantly as many as $96-99 \%$ of children could achieve full remission, and $50-60 \%$ of patients had a good prognosis (Dipiro et al., 2011 and Sabatine, 2014).

During the year 2010-2013, ALL is a disease with the highest incidence and mortality in Indonesia (Ministry of Health the Republic of Indonesia, 2015). The previous study reported that all leukemia patients in Yogyakarta, Indonesia had 35\% refused treatment, 23\% experienced treatment-related deaths, $22 \%$ suffered adverse conditions or relapsed, and 20\% recovered from illness (Mostert et al., 2010). That study illustrates the current general situation in Indonesia (The OncologyHematology Work Coordination Unit, Association of Indonesian Pediatricians, 2013).

Although the drug plays an important role in the healing and prevention of illness, most patients develop drugrelated problems (DRPs). DRPs are conditions that potentially affects the desired outcome of the therapy. DRPs evolve immediately after administration of drug therapy and might affect the patient's clinical condition that is associated with patient morbidity and mortality (Pharmaceutical Care Network Europe, 2010). Many studies showed the consequences of DRPs, which include additional doctor visits, long-term treatments, hospitalization, polypharmacy and emergency room care (Baena et al., 2006). 
A study of DRPs in a children's ward at Zewditu Memorial Referral Hospital, Addis Ababa, Ethiopia showed the incidence of DRPs was 31.6\%. Dose-related problems had a notable percentage about 45 (42.5\%) of all DRPs. Drug-drug interactions (DDIs) occurred about $41(38.7 \%)$, and undesirable drug reactions were 9 (8.5\%) (Biarra et al., 2017).

The role of pharmacists in pharmaceutical care for pediatric patients is to plan an optimal drug therapy by considering pathophysiological changes, drug efficacy, and specific toxicity. Therefore, pharmacists play a vital role in detecting, preventing and overcoming drugrelated problems (Ministry of Health of the Republic of Indonesia, 2009). This study was conducted to evaluate the effect of clinical pharmacist's intervention in reducing the DRPs in pediatric acute lymphoblastic leukemia treated with chemotherapy at referral hospitals in Tangerang, Indonesia.

\section{METHODS}

This study was conducted in child ward of Tangerang District General Hospital and carried out as prospective design, a pre-post design before and after pharmacist's intervention over the period from January to March 2017. The study was approved by the Ethics Committee of the Faculty of Medicine University of Indonesia (No: 948 / UN2.F1 / ETIK / 2016). The sampling was conducted by purposive sampling and the selected sample was based on inclusion criteria, i.e., patients who have DRPs aged one month to $<18$ years old and undergo hospitalization or one day care chemotherapy. The exclusion criteria were relapsed childhood ALL patients and patients with incomplete medical record data.

The drug therapy details, laboratory parameters and demographic details of all inpatients were prospectively reviewed by a clinical pharmacist. During ward rounds, drug and dose selection, drug regimens and patients' drug use patterns were evaluated in order to identify DRPs as per Version 6.2 of the PCNE classification system. Pharmacist's interventions consisted of reporting and discussing identified DRPs during interviews with various recipients, including pediatrician, patients, pharmaceutical logistics clerks, nurses and nutritionists. The type of intervention was classified as either independent (i.e. specifically tailored to an individual recipient) or concurrent (i.e. provided to several or all recipients at the same time). It is important to note that each DRP could be targeted with more than one intervention. After the interventions, the pharmacist continued monitoring the patient until discharge, conducting further interventions as necessary for any subsequent DRPs. The overall number of clinical problems and the overall number and subtypes of DRPs before and after the intervention were calculated for every patient. Data were analyzed using the Statistical Package for the Social Sciences (SPSS), Version 23.0 (IBM Corp., Armonk, New York, USA). A Wilcoxon signed rank test was used to assess the differences between pre- and post-intervention DRPs. A Chi-squared test was used to assess the relationship between DRPs and risk factors such as nutritional status, type of ALL, comorbidities, the number of drug items and type of care.

\section{RESULTS AND DISCUSSION}

\section{Demographic and Clinical Data of Patients}

A total of 138 patients had met the inclusion requirements and had been recruited for the study, consisted of female $(52.9 \%)$ and male $(47.1 \%)$. Patients were the age at $>5$-10-years-old $(44.2 \%)$, yet they mostly suffered at the age of 4-years-old (17.4\%). It is consistent with the previous studies that indicated the incidence rates of leukemia in children occurred at the age of 2-5 years (Widiaskara et al., 2010; Ministry of Health of the Republic of Indonesia, 2011). Data on patient characteristics were shown in Table 1.

This study showed that the number of high risks (HR) ALL was more dominant (77.5\%). It might be due to the childhood ALL patients coming to the provincial referral hospital in more severe conditions due to the long initial diagnosis and referral process on the way up to the hospital. There is a possibility of an increased in cancer cells malignancy that often leads to a condition of hyperleukocytosis (leukocyte count $>50,000 /$ $\mathrm{mm}^{3}$ ). In contrast, other studies reported the number of standard risks (SR) childhood ALL is higher than inpatients at HR (Latamu et al., 2016). Another study at Cipto Mangunkusumo Hospital, Jakarta, Indonesia, also showed that $64.3 \%$ of the patients were SR childhood ALL (Permatasari et al., 2009).

Our results also found that the most common types of comorbidities were thrombocytopenia, anemia and, diarrhea. It is similar with the characteristic clinical symptoms of pediatric ALL, anemia $(<7 \mathrm{~g} / \mathrm{dL})$ at $43 \%$, normochromic normocytic, thrombocytopenia (severe, $<20,000$ cells $/ \mathrm{mm}^{3}$ ) at $28 \%$ of cases (Dipiro et al., 2014). Diarrhea is one of the infections that can be found in childhood ALL patients. The most common cause of diarrhea is excessive intestinal motility, either due to local irritation of the intestinal wall caused by bacterial and viral infection or due to the emotional stress. One of the main consequences of Leukemia is the inability of the immune system to defend the body from invasion of foreign matter. In leukemia, white blood cell counts can reach as high as $500,000 / \mathrm{mm}^{3}$, compared with a normal count of $7,000 / \mathrm{mm}^{3}$. However, because most cells are abnormal or immature, they are 
Table 1. Basic demographic and clinical data of patients ( $n=138$ patients)

\begin{tabular}{lll}
\hline Characteristic & Category & Total (\%) \\
\hline \multirow{2}{*}{ Age } & $1-5$ year-old & $47(34.1)$ \\
& $>5-10$ year-old & $61(44.2)$ \\
& $>10-15$ year-old & $28(20.3)$ \\
Sex & Male & $2(1.4)$ \\
& Female & $73(52.9)$ \\
Nutritional status & Good nutrition & $65(47.1)$ \\
& Malnutrition & $132(96.6)$ \\
ALL type & Standard risk & $6(4.4)$ \\
& High risk & $31(22.5)$ \\
Comorbidity & $1-3$ & $107(77.5)$ \\
& $>3$ & $134(97.1)$ \\
Drug used item & $1-5$ & $4(2.9)$ \\
& $>5$ & $116(84.1)$ \\
Type of care & One-day care chemotherapy & $22(15.9)$ \\
& Inpatient & $26(18.84)$ \\
\hline
\end{tabular}

not capable of performing their defense functions. As a result, infection or severe bleeding is the most frequent cause of death in leukemia patients. Bacteria/viruses can easily invade people with immunosuppression. The notorious cause of diarrhea is due to irritation from a virus or bacterial infection in the distal bowel or colon (Guyton and Hall, 2007). Besides of that, diarrhea may result from damage of gastrointestinal mucosal cells caused by chemotherapy. Antineoplastic drugs and antimetabolite groups, especially methotrexate, also have side effects on the digestive tract, bone marrow and oral mucosa (Boussios et al., 2012). Stomatitis, diarrhea, thrombocytopenia, leukopenia or any sudden decline in leukocyte and thrombocyte counts indicates of treatment discontinuation. It is done to prevent the fatal ulceration of the gastrointestinal tract, infections, and hemorrhages (Nafraldi, 2008).

\section{Treatment of Acute Lymphoblastic Leukemia Patients}

The total number of drugs given to childhood ALL patients in this study was 422 items consisting of 44 types of drugs. Methotrexate either intrathecal or intravenously was commonly used at $31.3 \%$ due to the most patients $(81.2 \%)$ were undergo a maintenance phase of chemotherapy which is given methotrexate tablet once a week. The use of drugs was followed by 6-mercaptopurine (29.1\%) and vincristine (3.1\%). Most of them received one to five items $(84.1 \%)$, and the others received more than five items $(15.9 \%)$.

The study was found that $96.6 \%$ of childhood ALL has good nutritional status. Nutrition status data was taken from the medical records that have been assessed by the hospital's nutrition department. Malnutrition has a significant effect on ALL treatment outcomes. There are several reasons for the decrease in nutrient intake, one of them is the presence of cytokines such as alpha necrosis tumors that cause anorexia. The effects of pro-inflammatory cytokines have been investigated as the cause of various metabolic phenomena in cancer. Other causes of the reduced intakes of nutrients that causing anorexia and gastrointestinal effects are the high doses of chemotherapy drugs and radiotherapy that leads to mucosal damaged or toxicity. Moreover, doseenhancing patterns, continuous infusion (versus bolus dose), and combination chemotherapy treatment also elevate the side effects. High doses of chemotherapy often cause painful oral mucositis, which reduces the nutritional intake of several weeks. The treatment effects on gastrointestinal including esophagitis and enteritis with malabsorption and diarrhea increased sensitivity to bitterness, resulting in reduced the nutritional intake and difficulty of oral supplementation (The OncologyHematology Work Coordination Unit-Association of Indonesian Pediatricians, 2013; Mostert et al., 2010).

\section{Identification of DRPs}

Identification of DRPs was performed according to PCNE classification system version 6.2 2010. A total of 177 DRPs were found, which $91.57 \%$ were actual DRPs and the remaining $8.43 \%$ were potential. The mean DRP per patient was 1.28 while the type of DRP was 164 types. The average type of DRP that occurs per patient was 1.19. The number of DRPs before pharmacist intervention was shown in Figure 1 and the description sub-domain of 


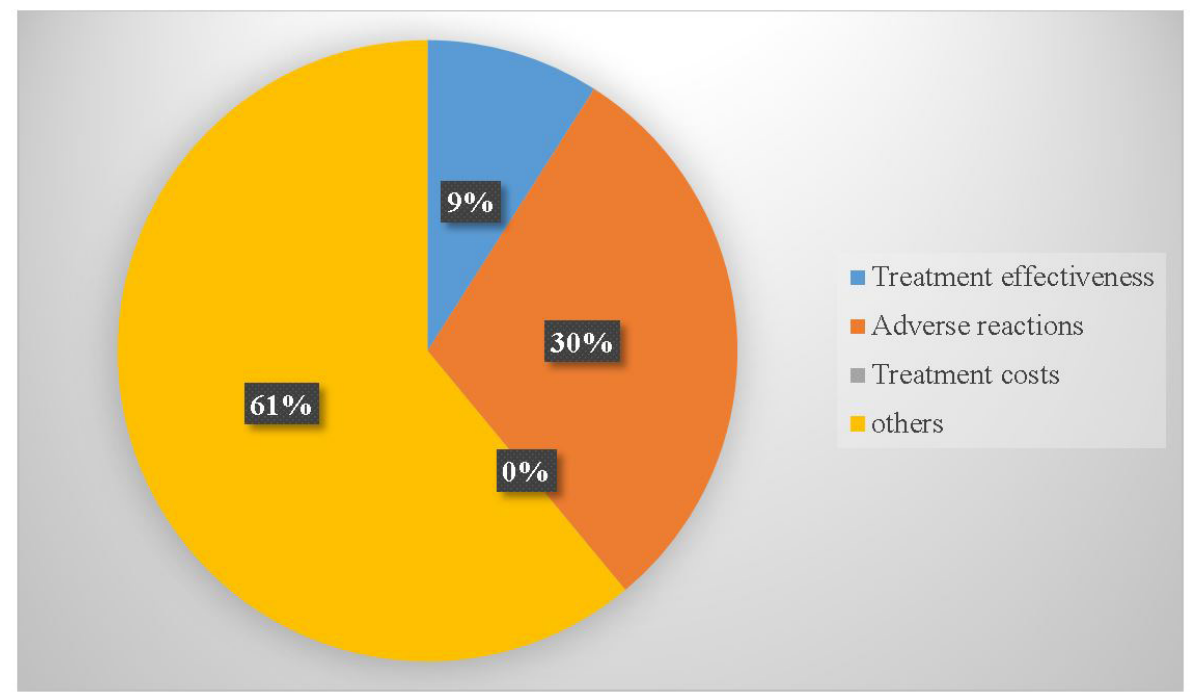

Figure 1. Number of DRPs of patients in the study before pharmacist's intervention ( $n=177$ DRPs)

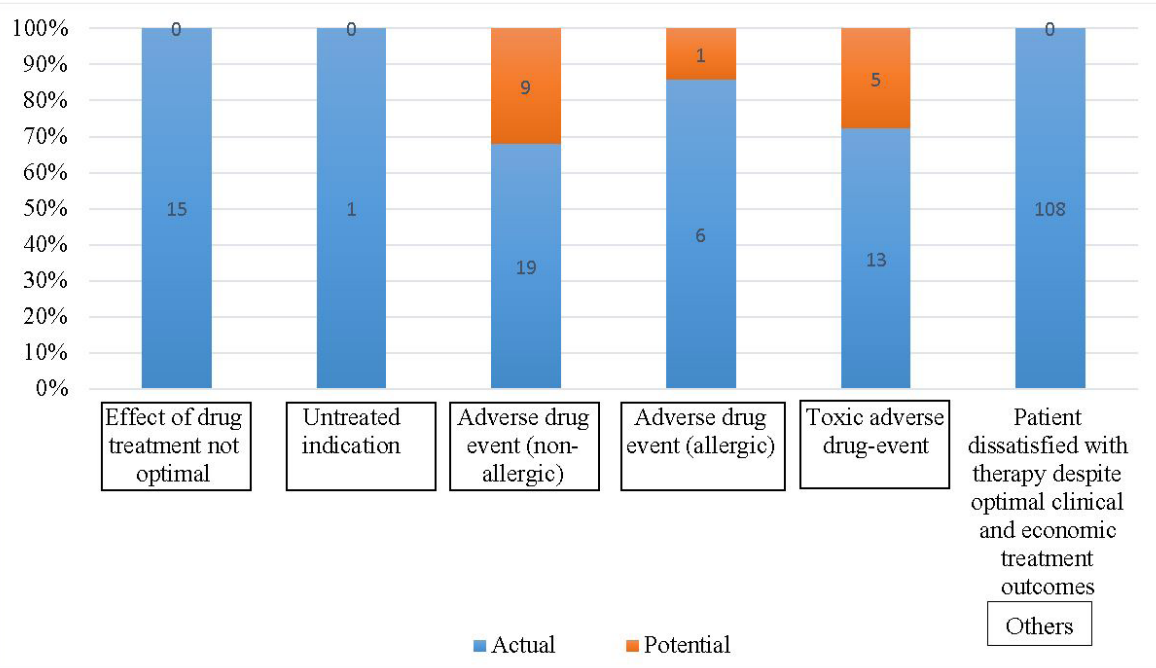

Figure 2. Sub-domain of DRPs of patients in the study before pharmacist's intervention ( $n=177$ DRPs)

DRPs was shown in Figure 2. We also identified types of DRPs with $61.02 \%$ were patient's dissatisfaction with the therapy they have received, $29.3 \%$ was non-allergic effects, and $8.48 \%$ was the not optimal effects of drugs. DRPs that occurred include the effectiveness of therapy (9.04\%), adverse drug reactions (ADRs) (29.94\%), treatment costs $(0 \%)$ and other problems $(61.02 \%)$. The most common causes of DRPs were associated with pharmaceutical logistics in which prescription drugs were not available $(62.1 \%)$, adverse events occurred in patients $(23.2 \%)$, and drug interactions $(5.6 \%)$. Data on number of DRPs and difference of DRPs before and after receiving pharmacist intervention characteristics were shown in Table 2.

The unavailable drug was methotrexate tablets used by childhood ALL patients in the maintenance phase, even though DPRs of methotrexate was the highest incidence because it has been used in every phase of HR and SR ALL chemotherapy. The duration of chemotherapy also a significant cause of DRPs. In the maintenance phase, chemotherapy regimens used methotrexate tablet once a week for SR. The maintenance phase started at week 13 and ended at week 110, while at HR started in 18 weeks and ended at week 118. Therefore, to overcome the problems, we gave counseling on the non-availability of methotrexate tablets and replaced the treatment with alternatives using methotrexate intravenous.

The effectiveness of drug was evaluated by comparing whether the dosage, method of use, interval, and duration of use were suitable with the indication for the childhood ALL patients in the literature or chemotherapy protocol, without monitoring the blood levels of the drug. The determination of DRPs in this study had several limitations among other studies, for example 
Table 2. Evaluation of decreased number of DRP after receiving pharmacist intervention January-March 2017

\begin{tabular}{|c|c|c|c|c|}
\hline $\begin{array}{l}\text { Primary } \\
\text { problem }\end{array}$ & Code & Problems & $\begin{array}{l}\text { Amount of DRPs } \\
\text { pre-intervention }\end{array}$ & $\begin{array}{l}\text { Amount of } \\
\text { DRPs post- } \\
\text { intervention }\end{array}$ \\
\hline \multirow{5}{*}{$\begin{array}{l}\text { Treatment } \\
\text { effectiveness }\end{array}$} & P 1.1 & No effect of drug treatment/ therapy failure & $0(0 \%)$ & $0(0 \%)$ \\
\hline & P 1.2 & Effect of drug treatment not optimal & $15(8.48 \%)$ & $2(1.13 \%)$ \\
\hline & P 1.3 & Wrong effect of drug treatment & $0(0 \%)$ & $0(0 \%)$ \\
\hline & P 1.4 & Untreated indication & $1(0.66 \%)$ & $0(0 \%)$ \\
\hline & & Total & $16(9.04 \%)$ & $2(1.13 \%)$ \\
\hline \multirow{4}{*}{$\begin{array}{l}\text { Adverse } \\
\text { reactions }\end{array}$} & P 2.1 & Adverse drug event (non-allergic) & $28(15.82 \%)$ & $6(3.39 \%)$ \\
\hline & P 2.2 & Adverse drug event (allergic) & $7(3.95 \%)$ & $0(0 \%)$ \\
\hline & P 2.3 & Toxic adverse drug-event & $18(10.12 \%)$ & $2(1.13 \%)$ \\
\hline & & Total & $53(29.94 \%)$ & $8(4.52 \%)$ \\
\hline \multirow{3}{*}{$\begin{array}{l}\text { Treatment } \\
\text { costs }\end{array}$} & P 3.1 & Drug treatment more costly than necessary & $0(0 \%)$ & $0(0 \%)$ \\
\hline & P 3.2 & Unnecessary drug-treatment & $0(0 \%)$ & $0(0 \%)$ \\
\hline & & Total & $0(0 \%)$ & $0(0 \%)$ \\
\hline \multirow{4}{*}{ Others } & P 4.1 & Patient dissatisfied with therapy despite & $108(61.02 \%)$ & $0(0 \%)$ \\
\hline & & $\begin{array}{l}\text { optimal clinical and economic treatment } \\
\text { outcomes }\end{array}$ & & \\
\hline & P.4.2 & $\begin{array}{l}\text { Unclear problem/complaint. Further } \\
\text { clarification necessary }\end{array}$ & $0(0 \%)$ & $0(0 \%)$ \\
\hline & & Total & $108(61.02 \%)$ & $0(0 \%)$ \\
\hline \multicolumn{3}{|c|}{ Total of DRP Found } & 177 & 10 \\
\hline \multicolumn{3}{|c|}{$\begin{array}{l}\text { Difference of DRP before and after receiving pharmacist } \\
\text { intervention }\end{array}$} & \multicolumn{2}{|c|}{$167(94.35 \%)$} \\
\hline
\end{tabular}

there is no examination of allergy with skin pricks test or measurement of specific immunoglobulin E (IgE) levels in the blood to decide if the patient has allergic adverse drug reactions (ADRs). Determination of patients experiencing allergic ADRs could be measured if there are signs and symptoms of a real allergy. For example, red bumps appear in the skin that repeatedly occur, eyelids and swollen lips, shortness of breath that is not caused by other diseases, dry skin, redness as well as itching recurring in typical locations such as the cheek area, elbow folds, behind the knee, and based on the results of a specialist skin examination. This study also did not examine the levels of drugs in the blood to evaluate potentially/suffering from toxic effects. The determination of potentially/suffering patient's toxic effects was evaluated by checking whether the patient receives drugs that are at the risk of organ toxicity according to the literature and performing laboratory investigation of related organ function.

\section{Evaluation of Pharmacist Interventions}

In this study, most of the clinical pharmacist interventions had been well received by health professions and patients $(94.9 \%)$ in Tangerang District General Hospital. The target of dominant interventions was physicians, patients, nurses, and the pharmaceutical department which amounted to $93.6 \%$ of 177 DRPs. Clinical pharmacist interventions were performed to reduce the incidence of DRPs and have a positive effect on drug therapy services in childhood ALL patients, but not all interventions were accepted and performed in this study. A total of nine DRPs were not intervened because four of them were not intervened by pharmacists, merely by doctors. The other two DRPs were not intervened because no electrolyte examination was performed to monitor the risk of hypocalcemia caused by the interaction of dexamethasone (corticosteroid) with furosemide (loop diuretic). Three interventions on DRPs were also not accepted by doctors because two interventions could not be performed due to unavailability of facilities and infrastructure for a liver biopsy to monitor the risk of methotrexate hepatotoxicity after accumulation dose of $4 \mathrm{~g}$ followed by the increase of $1.5 \mathrm{~g}$ doses. Another one intervention was not accepted regarding the clinical condition of patients suffering from hypocalcemia due to Lysis Syndrome Tumors (TLS). The physician was 
Table 3. Change of number and type of DRPs with risk factors of patients after receiving pharmacist intervention $(n=138$ patients)

\begin{tabular}{|c|c|c|c|c|c|c|c|c|c|}
\hline \multirow[b]{2}{*}{ Risk Factor } & \multirow[b]{2}{*}{ Category } & \multicolumn{2}{|c|}{$\begin{array}{c}\text { Change in number of } \\
\text { DRP }\end{array}$} & \multirow[b]{2}{*}{ Total } & \multirow[b]{2}{*}{$\underset{\text { value }}{p}$} & \multicolumn{2}{|c|}{ Change in type of DRP } & \multirow[b]{2}{*}{ Total } & \multirow[b]{2}{*}{ P value } \\
\hline & & $\begin{array}{l}\text { Decreased } \\
(\%)\end{array}$ & $\begin{array}{c}\text { Constant/ } \\
\text { Increased } \\
(\%) \\
\end{array}$ & & & $\begin{array}{l}\text { Decreased } \\
(\%)\end{array}$ & $\begin{array}{l}\text { Constant/ } \\
\text { Increased } \\
(\mathbf{\%})\end{array}$ & & \\
\hline $\begin{array}{l}\text { Nutritional } \\
\text { status }\end{array}$ & $\begin{array}{l}\text { Good } \\
\text { Malnutrition }\end{array}$ & $\begin{array}{l}131(99.2) \\
1(0.8)\end{array}$ & $\begin{array}{l}6(100) \\
0(0)\end{array}$ & $\begin{array}{l}137 \\
1\end{array}$ & 0.957 & $\begin{array}{l}131(99.2) \\
6(100)\end{array}$ & $\begin{array}{l}1(0.8) \\
0(0)\end{array}$ & $\begin{array}{l}132 \\
6\end{array}$ & 0.085 \\
\hline ALL type & $\begin{array}{l}\text { SR } \\
\text { HR }\end{array}$ & $\begin{array}{l}31(100) \\
106(99.3)\end{array}$ & $\begin{array}{l}0(0) \\
1(0.9)\end{array}$ & $\begin{array}{l}31 \\
107\end{array}$ & 0.775 & $\begin{array}{l}31(100) \\
105(98.1)\end{array}$ & $\begin{array}{l}0(0) \\
2(1.9)\end{array}$ & $\begin{array}{l}31 \\
107\end{array}$ & 0.600 \\
\hline Comorbidity & $\begin{array}{r}1-3 \\
>3\end{array}$ & $\begin{array}{l}133(99.3) \\
4(100)\end{array}$ & $\begin{array}{l}1(0.7) \\
0(0)\end{array}$ & $\begin{array}{l}134 \\
4\end{array}$ & 0,971 & $\begin{array}{l}132(98.5) \\
4(100)\end{array}$ & $\begin{array}{l}2(1.5) \\
0(0)\end{array}$ & $\begin{array}{l}134 \\
4\end{array}$ & 0.943 \\
\hline $\begin{array}{l}\text { Number of } \\
\text { drugs used }\end{array}$ & $\begin{array}{l}1-5 \\
>5\end{array}$ & $\begin{array}{l}116(100) \\
21(95.5)\end{array}$ & $\begin{array}{l}0(0) \\
1(4.5)\end{array}$ & $\begin{array}{l}116 \\
22\end{array}$ & 0.159 & $\begin{array}{l}116(100) \\
20(90.9)\end{array}$ & $\begin{array}{l}0(0) \\
2(9.1)\end{array}$ & $\begin{array}{l}116 \\
22\end{array}$ & $0.024 *$ \\
\hline Type of care & $\begin{array}{l}\text { ODC } \\
\text { Inpatient }\end{array}$ & $\begin{array}{l}112(100) \\
25(96.2)\end{array}$ & $\begin{array}{l}0(0) \\
1(3.8)\end{array}$ & $\begin{array}{l}112 \\
26\end{array}$ & 0.118 & $\begin{array}{l}112(100) \\
24(92.3)\end{array}$ & $\begin{array}{l}0(0) \\
2(7.7)\end{array}$ & $\begin{array}{l}112 \\
26\end{array}$ & $0.034^{*}$ \\
\hline
\end{tabular}

$\mathrm{SR}=$ standard risk, $\mathrm{HR}=$ high risk, $\mathrm{ODC}=$ One-day Care Chemotherapy, ${ }^{*}$ statistically significant $(\mathrm{p}<0.05)$

worried if the intravenous calcium given, the TLS would be worsening.

Bivariate analysis was conducted using the Wilcoxon Sign Rank test to determine the effect of clinical pharmacist intervention on the number and type of DRPs before and after the intervention. The results showed that there was a notable change in the number of DRPs with the mean value before the intervention was decreased from 1.28 to 0.07 after the intervention. Moreover, the reduction of mean value in the type of DRPs also occurred at 1.19 before the intervention to 0.07 after the intervention. Evaluation of decreased number and type of DRP after receiving pharmacist intervention was shown in Table 2.

The Fisher exact bivariate analysis was used to identify correlations between nutritional status, type of ALL, comorbidity, the number of drug items, and type of care that could decrease the number and type of DRPs of childhood ALL before and after clinical pharmacist intervention. The change of number and type of DRPs with risk factors of patients after receiving pharmacist intervention was shown in Table 3. The results showed that the number of drugs used and the type of care significantly affected the decrease in the type of DRPs $(p<0.05)$. Several previous studies showed the amount of drug administered to patients is an important risk factor for the occurrence of DRPs (Ibrahim N et al., 2013; PCNE, 2010; Rashed AN et al., 2014; Rashed AN et al., 2012). More complex drug therapy due to the presence of disease complications leads to a higher risk of DRPs such as side effects, drug interactions, medication errors, and noncompliance. It occurs because in this case the more drugs will be consumed.

Logistic regression multivariate analysis was conducted to see the most dominant risk factors for the decrease type of DRPs. The test results showed a none significant difference of risk factor effect on the decrease type of DRPs ( $>0.05)$. This study reported that the decrease in the number and type of DRPs in childhood ALL patients in Tangerang District General Hospital is due to the success of the pharmacist intervention in preventing potential DRPs and completing the actual DRPs.

\section{CONCLUSION}

This prospective study found that DRPs among childhood ALL patients were significantly reduced following a clinical pharmacist intervention amount to $94.35 \%$. The number of DRPs identified with childhood ALL inpatients and patients who underwent one day care chemotherapy at the Tangerang District General Hospital was 177 problems which consisted of 164 types of problems. DRPs that occurred include the effectiveness of therapy (9.04\%), adverse drug reactions (ADRs) $(29.94 \%)$, treatment costs $(0 \%)$ and other problems $(61.02 \%)$. The risk factors of nutritional status, type of LLA, number of comorbidities, number of drug items and type of treatment did not give a significant effect to reduce the number and type of DRPs $(p>0.05)$. These 
findings indicate that a pharmacist intervention can optimize therapy of childhood ALL patients.

\section{ACKNOWLEDGEMENT}

The authors wish to acknowledge the aid of the Director and the Head of Pharmaceutical Installation for granting permission for the study to be performed at the hospital. In addition, the authors would like to thank Firmanti and Indira Wiedati, pharmacist supervisors. All other parties who assisted with this study are also acknowledged.

\section{REFERENCES}

Baena, M.I., Fau,s M.J., Fajardo, P.C., Luque, F.M., Sierra, F., Martinez-Olmos, J., et al. (2006). Medicinerelated problems resulting in emergency department visits. European Journal Clinical Pharmacology, 62(5), 387-93.

Basic Health Research 2013. (2013). Indonesia: Agency for Health Research and Development, Ministry of Health, RI. doi: 10.1007 / s13398-014-0173-7.2

Biarra, M.K., Heye, T.B., Shibeshi, W. (2017). Assessment of drug-related problems in the pediatric ward of Zewditu. International Journal of Clinical Pharmacology. doi : 10.1007/s11096-017-0504-9

Boussios, S., Pentheroudakis, G., Katsanos, K., and Pavlidisa, N. (2012). Systemic treatment-induced gastrointestinal toxicity: incidence, clinical presentation, and management. Annals Gastroenterology, 25(2), 106118.

Dipir,o J.T., Talbert, R.L., Yee, G.C., Matzk,e G.R., Wells, B.G., and Posey, L.M. (2011). Pharmacotherapy a pathophysiologic approach ( $\left.8^{\text {th }} \mathrm{ed}\right), 2377-2387$, USA: The McGraw-Hill Medical.

Guyton, A., Hall, J.E. (2007) Pertahanan tubuh terhadap infeksi: Leukosit, granulosit, sistem monosit-makrofag, dan inflamasi. Dalam: Buku Ajar Fisiologi Kedokteran Edisi ke-11. Jakarta: Penerbit Buku Kedokteran EGC. h: 450-9.

Hidayat, R., Gatot, D., Djer, M.M. (2014). Validation of rondinelli scoring system to detect serious infections complications of acute lymphoblastic leukemia patients with neutropenia fever during induction phase of chemotherapy. Sari Pediatric, 15, 325-51. DOI: 10.14238/sp15.5.2014.325-31

Ibrahim, N., Wong, I.C., Patey, S., Tomlin, S., Sinha, M.D., Jani, Y. (2013). Drug-related problem in children with chronic kidney disease. Pediatric Nephrology, 28(1), 25-31.

Latamu, F., Jeanette, I.M., Mantik, M.J.F. (2017). Clinical features of diarrhea in pediatric patients with acute lymphoblastic leukemia with chemotherapy. E-Clinic Journals (ECJ), 5(1), January-June.

Ministry of Health of the Republic of Indonesia. (2009). Guidelines for pharmaceutical services for pediatric patients. Jakarta: Directorate of Community Pharmacy and Clinic DG of Pharmaceutical and Medical Devices of the Ministry of Health of the Republic of Indonesia.

Ministry of Health of the Republic of Indonesia. (2011). Guidelines for early discovery of cancer in children. Jakarta: Directorate of Non-Communicable Disease Control, Ministry of Health of the Republic of Indonesia.

Ministry of Health of the Republic of Indonesia. (2015). Bulletin window data and health information situation of cancer diseases. Jakarta: Data and Information Center, Ministry of Health Republic of Indonesia.

Mostert, S., Sitaresmi, M.N., Gundy, C.M., Janes, V., Sutaryo., Veerman, A.J.P. (2010). Comparing childhood leukemia treatment before and after the introduction of a parental education programme in Indonesia. Archives Disease Child, 95, 20-25. doi:10.1136/adc.2008.154138.

Nafrialdi, dan S. Gan. (2007). Antikanker dalam farmakologi dan terapi edisi 5. Jakarta: Bagian Farmakologi Fakultas Kedokteran Universitas Indonesia.

Permatasari, E., Windiastuti, E., Satarri, H.I. (2009). Survival and prognostic factors of childhood acute lymphoblastic leukemia. Paediatrica Indonesiana, 49, 365-371.

Pharmaceutical Care Network Europe Foundation (PCNE). (2010). Classification for Drug-related problems V 6.2, 1-9.

Rashed, A.N., Neubert, A., Tomlin, S., Jackman, J., Alhamdan, H., AlShaikh, A., et al. (2012). Epidemiology and potential associated risk factors of drug-related problems in hospitalized children in the United Kingdom and Saudi Arabia. European Journal of Clinical Pharmacology, 68(12), 1657-66.

Rashed, A. N., Wilton, L., Lo, C. C. H., Kwong, B. Y. S., Leung, S., \& Wong, I. C. K. (2014). Epidemiology and potential risk factors of drug-related problems in Hong Kong paediatric wards. British Journal of Clinical Pharmacology, 77(5), 873-879. https://doi.org/10.1111/ bcp. 12270 
Sabatine, M.S. (2014). Pocket medicine $5^{\text {th }}$ Ed The massachusetts general hospital handbook of internal medicine. USA: Wolter Kluwer Health and Lippincott Williams and Wilkins, Inc.

The Oncology-Hematology Work Coordination Unit, Association of Indonesian Pediatricians. (2013). Treatment protocol for acute lymphoblastic leukemia 2013 (Indonesian Childhood ALL - 2013 Protocol). The Oncology-Hematology Work Coordination Unit, IDAI. Jakarta.
Widiaskara, I.M., Permono, B., Ugrasena, I., and Ratwita, M. (2010). The outcome treatment of induction phase of acute lymphoblastic leukemia in children in Dr. Soetomo Hospital, Surabaya. Sari Pediatric, 12, 128-134.

World Health Organization. (2017). Childhood cancer day: How common are childhood cancers? 